\title{
Making Tactful Objects for Sensitive Settings
}

\author{
A Research through Design Process
}

\author{
PATRIZIA, D'OLIVO \\ Dept. Human-Centered Design, Delft \\ University of Technology, \\ Netherlands \\ p.dolivo@tudelft.nl
}

\author{
MARCO C., ROZENDAAL \\ Dept. Human-Centered Design, Delft \\ University of Technology, \\ Netherlands \\ m.c.rozendaal@tudelft.nl
}

\author{
ELISA, GIACCARDI \\ Dept. Human-Centered Design, Delft \\ University of Technology, \\ Netherlands \& Umeå Institute of \\ Design, Umeå, Sweden \\ e.giaccardi@tudelft.nl
}

\begin{abstract}
This contribution illustrates the Research through Design process of Mr.V the Spaceman, a tactful object meant to support families of children with cancer maintain a healthy domestic life during stressful times. By recounting insights from the field and unfolding changes to the original artifact over a period of two years, the paper illuminates how an understanding of tactfulness has emerged and developed into a key design quality for this work. This complex and entangled process of making is surfaced and illustrated by a rich and scrupulous annotation of the artisanal craft and technological explorations that led from the original Mr.V prototype to what is now Mr.V the Spaceman.
\end{abstract}

\section{CCS CONCEPTS}

- Human-centered computing; • Interaction design; • Interaction design process and methods; • Participatory design;

\section{KEYWORDS}

Tactfulness, Sensitive Settings, Childhood Cancer, Research Through Design, Objects with Intent, Tactful Objects

\section{ACM Reference Format:}

PATRIZIA, D'OLIVO, MARCO C., ROZENDAAL, and ELISA, GIACCARDI 2020. Making Tactful Objects for Sensitive Settings: A Research through Design Process. In Proceedings of the 11th Nordic Conference on HumanComputer Interaction: Shaping Experiences, Shaping Society (NordiCHI '20), October 25-29, 2020, Tallinn, Estonia. ACM, New York, NY, USA, 7 pages. https://doi.org/10.1145/3419249.3420140

\section{INTRODUCTION}

Disruptive life events such as sickness, divorce, or relocation may unexpectedly occur and significantly impact contexts of everyday life [31]. When affected by disruptive life events, people become vulnerable [2] and find it difficult to maintain 'normal' interactions and routines [37]. Designing for sensitive settings calls for more than emphatic sensitivity in the research process [13, 33, 45]. It requires a sensitive and thoughtful approach also in defining the

Permission to make digital or hard copies of all or part of this work for personal or classroom use is granted without fee provided that copies are not made or distributed for profit or commercial advantage and that copies bear this notice and the full citation on the first page. Copyrights for components of this work owned by others than the author(s) must be honored. Abstracting with credit is permitted. To copy otherwise, or republish, to post on servers or to redistribute to lists, requires prior specific permission and/or a fee. Request permissions from permissions@acm.org.

NordiCHI '20, October 25-29, 2020, Tallinn, Estonia

(c) 2020 Copyright held by the owner/author(s). Publication rights licensed to ACM ACM ISBN 978-1-4503-7579-5/20/10 . \$ \$15.00

https://doi.org/10.1145/3419249.3420140 design qualities and role that research artifact and technology introduced in disrupted lives may have [11]. But how can designers imbue qualities of tactfulness in artifacts and technologies meant for sensitive settings?

In this contribution we describe the Research through Design (RtD) process [43] behind the design of Mr.V, a tactful object for families dealing with childhood cancer. By unpacking insights from the field and unfolding changes to the original artifact over a period of two years, we explain how 'tactfulness' was conceptualized and articulated, and we annotate the four design principles that emerged from the process as key to the design of tactful objects and their expressive interactive qualities [39]. Based on these principles, we then define tactful objects as everyday objects that express their intention and act with respect for people's vulnerabilities and circumstances, providing a support that is not experienced to be stigmatizing or patronizing.

\section{RESEARCH THROUGH DESIGN PROCESS}

The work was carried out in collaboration with the biggest pediatric oncology institute in the Netherlands, with the intention to explore how design could foster the psychosocial development of children in treatment. The first author familiarized initially with child development theory [3], research and activities conducted at the institute, and participated to a cancer survivor meeting to better understand needs and concerns of children and their family members. Details of this field exploration and description of the emerged needs are thoroughly described in [10].

The preliminary sensitization process showed that during treatment the child development is strongly influenced by how the family manage to preserve a sense of 'normality' in everyday communication, interactions and routines and that this has influence on relaxation, family cohesion and resilience $[1,42]$. However, supportive and preventative interventions in pediatric cancer care focus mainly on the child, and are developed for use within the hospital environment $[21,30]$. Following this, we developed some initial artifacts [9] and conducted a first cycle of deployments and field studies with families dealing with childhood cancer. We wanted to investigate how a particular type of interactive artifacts, namely "Object with Intent" [40], could be used to help families of children with cancer maintain a healthy family life through communication and daily interaction, also during stressful times. A detailed description of this first iteration can be found in [8]. In this paper, we focus on the one artifact to which families responded more positively and which then we further developed, Mr.V. 

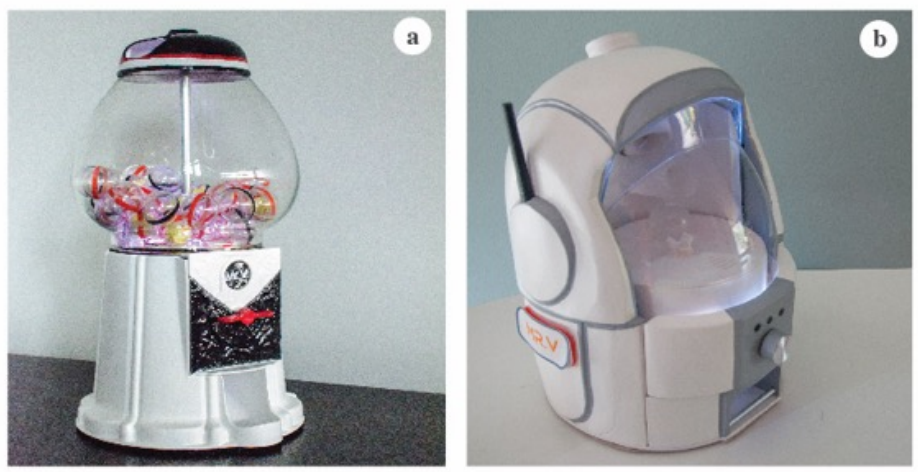

Figure 1: a) First prototype of Mr.V and b) final prototype of Mr.V the Spaceman. Copyright $\odot$ Patrizia D’Olivo

Inspired by work on everyday computational objects and slow technology like "Ritual Machines" [27], "Transformational Products" [29], "Photobox" and "Slow Game" [34, 35], we envisioned a playful object that could trigger family interaction at home to stimulate distraction and relaxation. The object would invite each family member to think about activities they like to share with their beloved, write down those ideas, and feed them to the object. The object would then dispense the notes randomly as surprises, encouraging family members to engage in fun activities that would turn everyday moments into special ones. Informed by this initial design vision, we developed the first working prototype of Mr.V. The artifact resembled a vintage vending machine for chewing gums. An Arduino ${ }^{\mathrm{TM}}$ controlled the rotating pierced disc that automatically dropped small plastic balls containing the notes-surprises at set times [8].

To deploy the prototype, we designed a study that was approved and conducted in accordance with the regulations of the Medical Ethical Committee of the University Medical Center Utrecht in the Netherlands. Given the contact with patients and the stressful situation lived by the families, together with one of the child life specialists involved in the project we introduced Mr.V in the home of four families in treatment for a limited period of one week per family. Successively, with the collaboration of the same child life specialist we conducted field observations where we collected impressions on how Mr.V was received, how it was used daily and where it was placed in the home. The data collection was performed through the use of different means such as: family diaries, WhatsApp ${ }^{\mathrm{TM}}$ encrypted chats were families shared pictures and videos with the researchers, semi-structured group interviews in each family home, and a questionnaire to rate multiple aspects of Mr.V. A detailed description of methods, analysis process and findings can be found in [8].

Four main themes emerged during the analysis, which account for the characteristics of tactful objects as a specific category of Objects with Intent [40]. Through the rich descriptions and visual references of this contribution, we aim to annotate the Research through Design process and empirical findings of this first deployment, and in particular the deliberate changes to the original artifact that led to the final prototype of Mr.V the Spaceman. Mr.V the Spaceman has been designed for a second deployment phase in the home of ten new families in treatment that is currently concluded and accounted for in [4]. The complex and entangled process of making tactful objects is surfaced and illustrated in this paper by a rich and scrupulous account of the artisanal craft and technological explorations that led from the original Mr.V prototype to the final prototype Mr.V the Spaceman (Figure 1a,b).

\section{CONTEXTUALIZING ENTANGLEMENTS OF ARTISANAL CRAFT AND TECHNOLOGICAL EXPLORATION}

This section annotates and visually collects the entanglement of the artisanal craft and technological exploration of affordances and interactional elements that have characterized this RtD process. The paper is structured according to four design principles. These principles emerged from the field study [8] as key to the design of tactful objects, that is, to the type of relation that these objects need to establish with people in order to be perceived as tactful in sensitive settings. For each principle, text and correlated images annotate: (a) how the first prototype was designed, (b) what insights were generated by the field study in relation to the object's design and expressiveness of tactfulness, and (c) what design choices were made that led to the new design of MrV the Spaceman. Through this rich and scrupulous annotation we intend to illuminate how tactfulness can be embodied in the design of an object for sensitive settings, and how the relationship between such object and people unfolds in sensitive settings. These annotations, and their organization according to the principles that later emerged from the field study, are not meant to provide systematic descriptions of the correlation between field insights and subsequent design change. Rather, they are meant to retroactively recognize and express the rich entanglements between the object's embodiment and expressiveness that were experienced in practice [39], and to emphasize how the agency of people and object characterizes the type of relation that takes shape in the sensitive setting $[7,20]$.

\subsection{Sensitive Partnership}

The first prototype of Mr.V was designed to encourage family interaction at home by randomly and playfully dispensing notes containing activities as surprises. The original Mr.V was meant to 

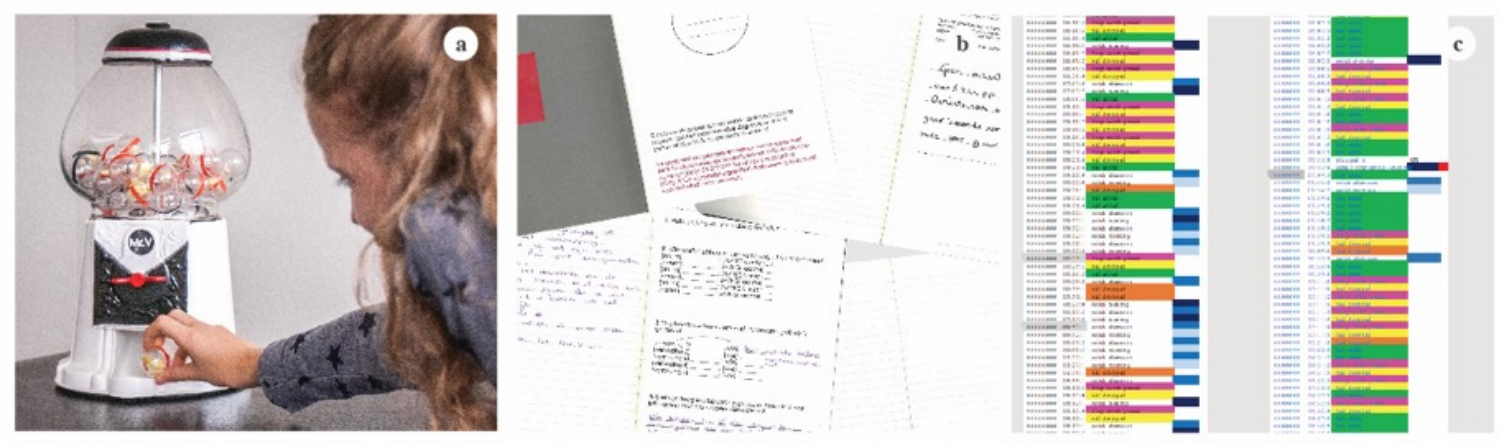

Figure 2: Sensitive partnership: (a) first prototype [8]: the object playfully dispenses activities as surprises; (b) field study [8]: families' diary annotations; (c) final prototype [4]: example of logbook with the data collected by Mr.V the Spaceman. Copyright @Patrizia D'Olivo

sensitively fulfill a supportive function by leveraging the family members' intrinsic motivation and channeling their strengths and capabilities (Figure 2a).

Participants explained that they saw Mr.V as a member of the family that reminded them to do things together in a playful way, and that they appreciated how its proactive behavior helped them to plan the activities. By dispensing surprises as a means to suggest family activities, the participants felt like Mr.V provided support without forcing them (Figure $2 b$ ).

In the new prototype, Mr.V the Spaceman, the object's role and simple behavior did not change. However, for the second deployment, we considered the opportunity to collect non-sensitive data through the object with the goal to help improve and better attune the support given to the families. Mr.V was thus upgraded to a data-enabled RtD artifact [16] and equipped with optic and pressure sensors to record data about its daily interactions in a logfile (e.g., how many time Mr.V is used, at what time the families prefer to receive the surprises, and when the surprises are requested at will) (Figure 2c). This addition provided the tactful object with the sensing capabilities needed to become autonomous in its behavior and more tactfully respond to changing needs and circumstances [48].

Through the field study [8], we understood that objects in sensitive settings are considered tactful when they establish a partnerships with humans [17] in a positive and non-stigmatizing way to foster wellbeing [38]. Even data-enabled, the new Mr.V the Spaceman should continue to empower family members by leveraging on their skills and competences (i.e., knowing each other's preferences and being creative) [18], embodying playful strategies (i.e., activities experienced as a surprise) [26] and providing a tangible representation of what is needed to fulfill the family's needs (i.e. delivering surprises as a way to signal that there's an opportunity for quality time together) [23].

\subsection{Balanced collaboration}

The first prototype of Mr.V reminded families to think about things and activities they like to do together, write them down on notes, enclose them in little round containers and place them into the device. These containers were then randomly dispensed by Mr.V (Figure 3a).

Families indicated that Mr.V provided a lot of openness, and this became slightly overwhelming when there were more then 60 containers to fill. Families felt pressured to come up with new ideas, but they tried to overcome the challenge by categorizing the content of the notes. Later on, the analysis of those categories provided information about the available resources and preferences of the families involved. At the same time, Mr.V also presented some restrictions because the surprises were dropped at pre-defined moments not chosen by the families. Families told us that they would have liked to control Mr.V's surprise schedule but that they didn't want to lose the surprise effect (Figure 3b).

In Mr.V the Spaceman, improvements were made to simplify the process of creating the activities. The number of containers decreased from 60 to 16, and a personal family booklet was added. The booklet contains a series of colored pages (four pages per color) with pre-cut stripes that family members can tear-off and use to write the surprises. The choice of using colored-pages is a subtle hint to facilitate the ideation phase and support the families in differentiating, for instance, the content/category of the surprises. To address the balance between surprise effect and control mentioned by the families, an interface was created to anticipate the dropping moment. The interface lets the family decide the timeframe in which they want to receive the surprise, yet it allows some unpredictability in when exactly $\mathrm{Mr} . \mathrm{V}$ will drop one. A frontal knob controls a timer and consent to choose a small range of hours between 'morning', 'afternoon', or 'evening'. Families can choose to receive a maximum of two automatically dispensed surprises a day. However, an 'emergency button' is available if they feel like they want to receive more surprises. This button looks like a toggle switch with safety cover that is positioned on the side of the machine, and if pressed, provides a surprise immediately (Figure 3c).

Through the field study [8], we understood that tactful objects should be designed to collaborate with people [41] by balancing the ways in which they steer towards desired forms of behavior [25] while also allowing freedom in appropriation and openness in use [5]. The collaboration between MrV the Spaceman's and 

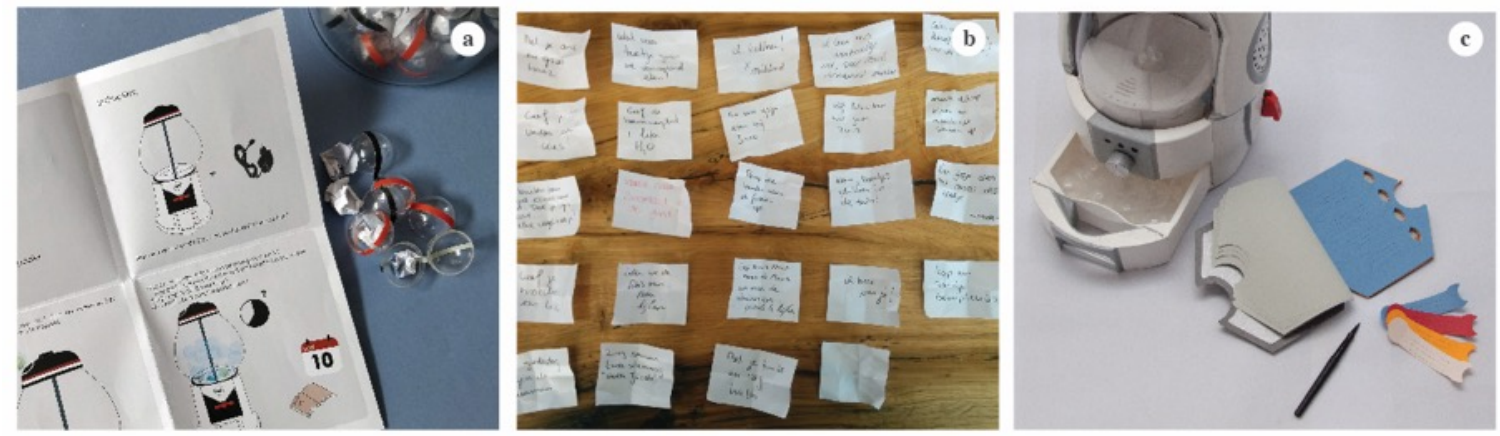

Figure 3: Balanced collaboration: a) first prototype [8]: probes given to interact with the first prototype; b) field study [8]: collection of family's activities; c) final prototype [4]: control interface, selected containers and booklet implemented in Mr.V the Spaceman. Copyright $\odot$ Patrizia D’Olivo

the families should be designed to evolve towards a form of coperformance [28] in which the object learns to perform practices alongside family members, and becomes day after day more tactful and aware of what they need 'in the moment'.

\subsection{Familiar character}

The appearance of the first Mr.V was designed to trigger positive childhood memories by using the metaphor of a 'chewing gum vending machine'. This also appealed to a form of interaction and use that people were familiar with [24]. The character of a machinelike dispenser was mingled with human-like features created by the addition of two ornamental elements resembling a 'bow tie' and 'hat' (Figure 4a).

In the field study [8], families appreciated Mr.V as being detailed, nicely crafted, appealing to both boys and girls, and to people of different ages. We further noticed how participants described Mr.V as 'new family member' or as a friendly and supportive 'co-parent'. However, parents tended to restrict its use to the sick child with only minor involvement of siblings. Therefore, we decided to work on the object's appearance by leveraging on its anthropomorphic aspects to improve the meaningful and emphatic connection between family and object, but also on the overall family-centered experience that would facilitate family members' inclusion (Figure 4b).

In the re-design of the character of Mr.V the Spaceman, we capitalized on its anthropomorphism by using a 'spaceman' metaphor without losing the machine dispenser familiar connotation. The human-like quality is triggered by its form of a 'little chubby spaceman' that still remains mysterious because it lacks facial features. An aesthetics was created that is not too childish in order to trigger interest also in parents and older siblings. Its human-like quality is further strengthened by the possibility of assign it a name, and write this name down on a little patch-tag that can be attached to its right 'arm' with Velcro ${ }^{\circledR}$. The new Mr.V was also designed as an integrated activity kit that avoids cluttering and enhances exploration. For instance, Mr.V's 'antenna' is the marker that can be used to write the surprises. The 'feet' of Mr.V prevent the dropped containers from rolling away and at the same time are the handles of a drawer useful to store unused containers and the booklet. Everything was designed to give a consistent experience linked to the 'spaceman' theme: MrV is packaged in a white box with translucent cover that can be closed with a safety belt. Upon introduction, the package is accompanied with a letter that tells the story of Mr.V 'coming from space' to bring surprises collected during its travels to the whole family (Figure 4c).

Through the field study [8], we understood that designing tactful objects for sensitive settings means to design objects capable to establish meaningful and emphatic connections with people [36] by looking familiar, by functioning in a trustworthy way, and by fitting within an overall experienced narrative [12]. In Mr.V the Spaceman we tried to balance the 'hybrid' [41] activity kit/spaceman aspect so that its humanoid appearance could trigger a form of 'quasi-other' relation [23] between the families and the object; and enhance the possibility to experience it as human-thing that adapts its character according to the family members it is interacting with.

\subsection{Discreet presence}

The previous Mr.V had a sustained presence in the home environment of the families and was always placed in the living room. However, we understood from the families that the sound produced by the object when a ball was dispensed did not feel consistent with the object's cheerfulness and playfulness. Furthermore, it was not possible to control the activity of the object and the families expressed some concern about being afraid to have to wake up during the night because of it (Figure 5a).

To make Mr.V the Spaceman better attuned to the home environment setting, the way it communicates through sound and light was redesigned. To trigger attention and excitement, Mr.V emits a radar-like sound 10 minutes before the dropping of the surprise within the chosen timeframe (i.e., morning, afternoon or evening). This event is accompanied by the flickering of white lights coming from within Mr.V and the shaking of the filled containers caused by the actuation of the base-plate on which they rest. During these 10 minutes, the flickering white lights slowly increase in intensity and frequency until the container is actually dropped. At the dropping moment a sparkling sound is emitted. Furthermore, a new set of sounds has been added to express that Mr.V 'wakes up' and 'goes to 

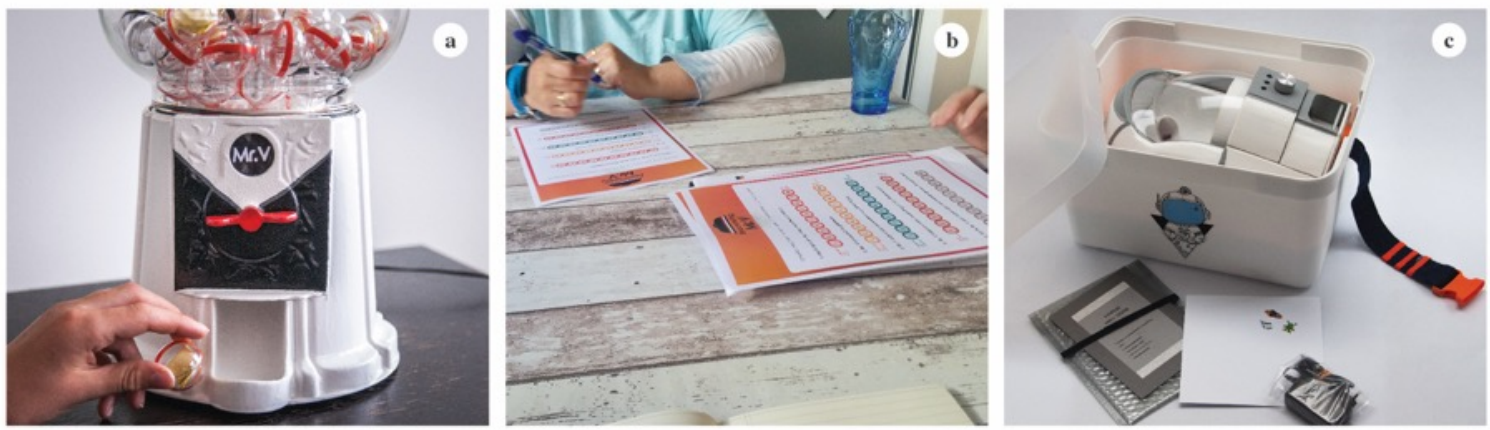

Figure 4: Familiar character: a) first prototype [8]: detail of Mr.V resembling a bow tie ; b) field study [8]: a participant rating Mr.V through a questionnaire; c) final prototype [4]: the introductory package of Mr.V the Spaceman. Copyright $\odot$ Patrizia D’Olivo
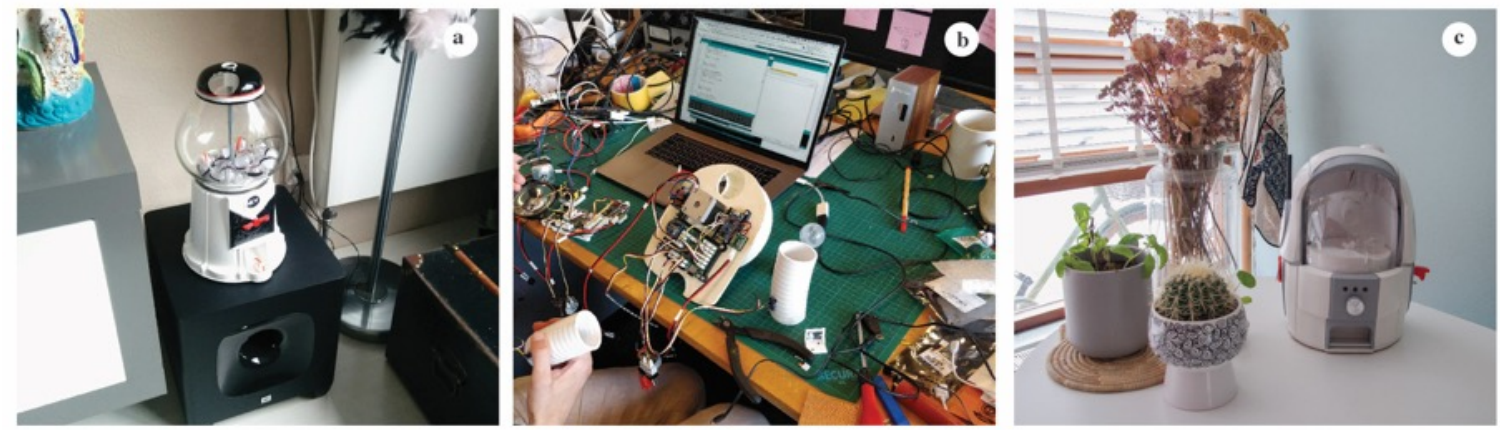

Figure 5: Discreet presence: a) first prototype [8]: Mr.V in one of the families' living room; b) field study [8]: implementation of new expressive features in Mr.V the Spaceman; c) final prototype [4]: Mr.V the Spaceman ready for a new deployment. Copyright $\odot$ Patrizia D’Olivo

sleep' respectively at 9:00 am in the morning and at 8:00 pm in the evening. These sounds are meant to strengthen the perception of Mr.V 'behaving' according to the scheduled rhythms of the family and also to assure that during the night the object will be inactive (Figure 5b,5c).

Through the field study [8], we understood that in order to tactfully communicate intent, trigger attention, and blend in the environment, objects should carefully orchestrate the different behaviors and their expressiveness [39] to prevent discomfort and misunderstanding [15], but also to trigger interest and create a pleasant serendipity [22]. The expressiveness of the new Mr.V the Spaceman should be able to accommodate its contextual state and allow a tactful presence that moves foreground and background [23] according to the daily situation of the family (i.e., good day, bad day, sudden crisis, school routine, holiday routine, etc.).

\section{CONCLUSION AND FUTURE WORK}

This paper described the Research through Design iterations that led to the design of Mr.V the Spaceman as a tactful object. The rich descriptions of results illustrate how principles of 'tactfulness' were embodied and expressed into the physical and digital crafting of an object, designed with the intent to empower families of children with cancer to maintain a healthy family life during stressful times at home. Particular attention was placed into how the making process connected empirical findings and design exploration, and how it contributed to a categorization of the type of relations that an interactive object should establish with people to be perceived as tactful in sensitive settings. These relations are encapsulated into the four principles that we used in the paper for retrospectively organizing the entanglements of artisanal craft and technological exploration that characterized this two-year long Research through Design process:

- Sensitive partnership. Tactful objects should be respectful of people's circumstances and vulnerabilities, and act as sensitive partners without stigmatizing or patronizing.

- Balanced collaboration. Tactful objects should balance people's intentions and their own intention, and be collaborative.

- Familiar character. Tactful objects should establish a meaningful familiar connection to people, and be inviting.

- Discreet presence. Tactful objects should position themselves with discretion within the setting in which they are embedded.

Through these principles we identify tactful objects as a category of "Object with Intent" [40], specifically designed with the purpose of 
establishing tactful and sensitive relationships with people in sensitive settings. A new and longer cycle of deployment has brought Mr.V the Spaceman in the home of other ten families in treatment. New insights have been collected on how to further develop Mr.V as a tactful object [4], but also on how to implement autonomous behavior in sensitive settings [47] as well as in everyday contexts [41] in a tactful way.

The conceptualization and exploration of tactful objects offered by this work contributes to illuminate new opportunities for both $\mathrm{HCI}$ researchers and practitioners interested in designing interactive artifacts for sensitive settings and healthcare [32, 44, 46]. It also instigates a more general reflection on how the growing sensing potential, interface complexity and agency of interactive artifacts should be developed without becoming intrusive and losing legibility and trust $[6,14,19]$.

\section{ACKNOWLEDGMENTS}

We would like to thank the reviewers for their insightful comments. We would like also to thank: Aadjan van der Helm, Chiwei Luu and Martin C. Havranek from ID-Studiolab (Delft University of Technology) for their technical supervision in the development of the prototypes; Gijs Leijdekkers and Beatrice Chichiarelli for the photographic support in documenting the design iteration of Mr.V and Mr.V the Spaceman respectively; Jet Peek, Minon Rosier and Rubi G. Vermeulen (Delft University of Technology) for their contribution in the data collection and processing; Charlotte J.A. van Aart, Jaap Huisman, Kelly L.A. van Bindsbergen and Martha A. Grootenhuis (Princess Maxima Center) for the support in the definition of the medical ethical protocol, the participants recruitment, and the supervision during the fieldwork; and all the families that dedicated their time to participate in this research. The work presented in this paper is part of the project "Meedoen=Groeien!". This research is a collaboration among HandicapNL, the Princess Max́ima Center of Pediatric Oncology, and Delft University of Technology. The Dutch Friends Lottery finances this project (Grant number: R2014047).

\section{REFERENCES}

[1] Melissa A. Alderfer and Anne E. Kazak. 2006. Family issues when a child is on treatment for cancer. Comprehensive handbook of childhood cancer and sickle cell disease: A biopsychosocial approach: 53-74.

[2] Jo Aldridge. 2016. Participatory research: Working with vulnerable groups in research and practice. Policy Press.

[3] Godwin S. Ashiabi and Keri K. O'Neal. 2015. Child Social Development in Context An Examination of Some Propositions in Bronfenbrenner's Bioecological Theory. SAGE Open 5, 2: 2158244015590840.

[4] Kelly L.A. van Bindsbergen, Patrizia D’Olivo, Marco C. Rozendaal, Johannes H.M. Merks, and Martha A. Grootenhuis. Support for Families at Home during Childhood Cancer Treatment: A Pilot Study with Mr.V the Astronaut. To appear in Supportive Care in Cancer.

[5] Boudewijn Boon, Marco C. Rozendaal, and Pieter J. Stappers. 2018. Ambiguity and open-endedness in behavioural design. DRS 20185

[6] Albert Borgmann. 1987. Technology and the character of contemporary life: A philosophical inquiry. University of Chicago Press.

[7] Nazli Cila, Iskander Smit, Elisa Giaccardi, and Ben Kröse. 2017. Products as agents: Metaphors for designing the products of the IoT age. In Proceedings of the 2017 CHI Conference on Human Factors in Computing Systems, 448-459.

[8] Patrizia D’Olivo, Kelly L. A. van Bindsbergen, Jaap Huisman, Martha A. Grootenhuis, and Marco C. Rozendaal. 2020. Designing tactful objects for sensitive settings: A case study on families dealing with childhood cancer. International Journal of Design 14, 2: 103-124.

[9] Patrizia D’Olivo, Marco C. Rozendaal, and Elisa Giaccardi. 2017. AscoltaMe: Retracing the Computational Expressivity of a Tactful Object for Sensitive Settings. In Proceedings of the 2017 Conference on Designing Interactive Systems, 943-955.
[10] Patrizia D'Olivo, Marco C. Rozendaal, Elisa Giaccardi, Martha A. Grootenhuis, and Jaap Huisman. 2018. Reconfiguring a New Normal: A Socio-Ecological Perspective for Design Innovation in Sensitive Settings. She fi: The fournal of Design, Economics, and Innovation 4, 4: 392-406. https://doi.org/10.1016/J.SHEJI.2018.10.003

[11] Hilary Davis and Jenny Waycott. 2015. Ethical encounters: HCI research in sensitive and complex settings. In Proceedings of the Annual Meeting of the Australian Special Interest Group for Computer Human Interaction, 667-669.

[12] Pieter Desmet and Paul Hekkert. 2007. Framework of product experience. International journal of design 1, 1: 57-66.

[13] Virginia Dickson-Swift, Erica L. James, and Pranee Liamputtong. 2008. Undertaking sensitive research in the health and social sciences: Managing boundaries, emotions and risks.

[14] Steven Dorrestijn and Peter-Paul Verbeek. 2013. Technology, wellbeing, and freedom: The legacy of utopian design. International fournal of Design 7, 3 .

[15] William Gaver, Phoebe Sengers, Tobie Kerridge, Joseph Kaye, and John Bowers. 2007. Enhancing ubiquitous computing with user interpretation: Field testing the home health horoscope. In Conference on Human Factors in Computing Systems Proceedings. https://doi.org/10.1145/1240624.1240711

[16] Elisa Giaccardi. 2019. Histories and futures of research through design: From prototypes to connected things. International Journal of Design 13, 3: 139-155.

[17] Elisa Giaccardi. 2019. Casting things as partners in design: Towards a more-thanhuman design practice. In Relating to Things: Design, Technology and the Artificial. London: Bloomsbury, forthcoming.

[18] Elisa Giaccardi, Lenneke Kuijer, Louis Neven, and others. 2016. Design for resourceful ageing: Intervening in the ethics of gerontechnology. Proceedings of DRS: $1-14$.

[19] Elisa Giaccardi and Johan Redström. 2020. Technology and More-Than-Human Design. Design Issues 36, 4.

[20] Sabrina Hauser, Doenja Oogjes, Ron Wakkary, and Peter-Paul Verbeek. 2018. An annotated portfolio on doing postphenomenology through research products. In Proceedings of the 2018 Designing Interactive Systems Conference, 459-471.

[21] Lotte Haverman, Vivian Engelen, Marion A.J. van Rossum, Hugo S.A. Heymans, and Martha A. Grootenhuis. 2011. Monitoring health-related quality of life in paediatric practice: Development of an innovative web-based application. $B M C$ Pediatrics. https://doi.org/10.1186/1471-2431-11-3

[22] John Helmes, Caroline Hummels, and Abigail Seilen. 2009. The other brother: Re-experiencing spontaneous moments from domestic life. In Proceedings of the 3rd International Conference on Tangible and Embedded Interaction, TEI'09. https://doi.org/10.1145/1517664.1517715

[23] Don Ihde. 1990. Technology and the lifeworld: From garden to earth.

[24] Lars-Erik Janlert and Erik Stolterman. 1997. The character of things. Design Studies 18, 3: 297-314.

[25] Jaap Jelsma. 2000. Design of behaviour steering technology.

[26] Flavius Kehr, Marc Hassenzahl, Matthias Laschke, and Sarah Diefenbach. 2012. A transformational product to improve self-control strength: the chocolate machine. In Proceedings of the SIGCHI Conference on Human Factors in Computing Systems, 689-694.

[27] David S. Kirk, David Chatting, Paulina Yurman, and Jo-Anne Bichard. 2016. Ritual machines I \& II: making technology at home. In Proceedings of the 2016 CHI Conference on Human Factors in Computing Systems, 2474-2486.

[28] Lenneke Kuijer and Elisa Giaccardi. 2018. Co-performance: Conceptualizing the role of artificial agency in the design of everyday life. In Proceedings of the 2018 CHI Conference on Human Factors in Computing Systems, 125.

[29] Matthias Laschke, Marc Hassenzahl, and Sarah Diefenbach. 2011. Things with attitude: Transformational Products. Create '11 Conference: 1-2.

[30] Meghan L Marsac, Aimee K Hildenbrand, Kathleen Clawson, Leela Jackson, Kristen Kohser, Lamia Barakat, Nancy Kassam-Adams, Richard Aplenc, Anne Vinsel, and Melissa A Alderfer. 2012. Acceptability and feasibility of family use of The Cellie Cancer Coping Kit. Supportive Care in Cancer 20, 12: 3315-3324.

[31] Michael Massimi, Jill P. Dimond, and Christopher A Le Dantec. 2012. Finding a new normal: the role of technology in life disruptions. In Proceedings of the acm 2012 conference on computer supported cooperative work, 719-728.

[32] Michael Massimi, Will Odom, David Kirk, and Richard Banks. 2010. HCI at the end of life: understanding death, dying, and the digital. In CHI'10 Extended Abstracts on Human Factors in Computing Systems, 4477-4480.

[33] Cosmin Munteanu, Heather Molyneaux, and Susan O’Donnell. 2014. Fieldwork with vulnerable populations. interactions $21,1: 50-53$.

[34] William T. Odom, Abigail J. Sellen, Richard Banks, David S. Kirk, Tim Regan, Mark Selby, Jodi L. Forlizzi, and John Zimmerman. 2014. Designing for Slowness, Anticipation and Re-visitation: A Long Term Field Study of the Photobox. In Proceedings of the 32Nd Annual ACM Conference on Human Factors in Computing Systems (CHI '14), 1961-1970. https://doi.org/10.1145/2556288.2557178

[35] William Odom, Ron Wakkary, Ishac Bertran, Matthew Harkness, Garnet Hertz, Jeroen Hol, Henry Lin, Bram Naus, Perry Tan, and Pepijn Verburg. 2018. Attending to slowness and temporality with olly and slow game: A design inquiry into supporting longer-term relations with everyday computational objects. In Proceedings of the 2018 CHI Conference on Human Factors in Computing Systems, 1-13. 
[36] Daniel Orth, Clementine Thurgood, and Elise van den Hoven. 2018. Designing objects with meaningful associations. International fournal of Design 12, 2: 91-104

[37] Joän M. Patterson, Kristen E. Holm, and James G. Gurney. 2004. The impact of childhood cancer on the family: A qualitative analysis of strains, resources, and coping behaviors. Psycho-Oncology: Fournal of the Psychological, Social and Behavioral Dimensions of Cancer 13, 6: 390-407.

[38] Ann Petermans and Rebecca Cain. 2019. Design for Wellbeing: An Applied Approach. Routledge.

[39] Johan Redström. 2008. Tangled interaction: On the expressiveness of tangible user interfaces. ACM Transactions on Computer-Human Interaction (TOCHI)15, 4 $1-17$.

[40] Marco Rozendaal. 2016. Objects with intent: a new paradigm for interaction design. interactions 23, 3: 62-65.

[41] Marco C. Rozendaal, Boudewijn Boon, and Victor Kaptelinin. 2019. Objects with Intent: Designing Everyday Things as Collaborative Partners. ACM Transactions on Computer-Human Interaction (TOCHI)26, 4: 26.

[42] Susana Santos, Carla Crespo, M Cristina Canavarro, and Anne E Kazak. 2015 Family rituals and quality of life in children with cancer and their parents: The role of family cohesion and hope. Journal of pediatric psychology 40, 7: 664-671.

[43] Pieter Stappers and Elisa Giaccardi. 2017. Research through Design. The Encyclopedia of Human-Computer Interaction, 2nd ed.; Idea Group Reference: Hershey, PA,
USA: $1-94$.

[44] Anja Thieme, John Vines, Jayne Wallace, Rachel Elizabeth Clarke, Petr Slovák, John McCarthy, Michael Massimi, and Andrea Grimes Grimes Parker. 2014. Enabling Empathy in Health and Care: Design Methods and Challenges. In CHI '14 Extended Abstracts on Human Factors in Computing Systems (CHI EA '14), 139-142. https://doi.org/10.1145/2559206.2559237

[45] John Vines, Róisín McNaney, Stephen Lindsay, Jayne Wallace, and John McCarthy. 2014. Special Topic: Designing for and with Vulnerable People. interactions 21, 1: 44-46. https://doi.org/10.1145/2543490

[46] Torben Wallbaum, Janko Timmermann, Wilko Heuten, and Susanne Boll. 2015. Forget me not: Connecting palliative patients and their loved ones. In Proceedings of the 33rd Annual ACM Conference Extended Abstracts on Human Factors in Computing Systems, 1403-1408.

[47] Jenny Waycott, Greg Wadley, Stefan Schutt, Arthur Stabolidis, and Reeva Lederman. 2015. The Challenge of Technology Research in Sensitive Settings: Case Studies in'ensitive HCI'. In Proceedings of the Annual Meeting of the Australian Special Interest Group for Computer Human Interaction, 240-249.

[48] Michael Wooldridge and Nicholas R. Jennings. 1995. Intelligent agents: Theory and practice. The knowledge engineering review 10, 2: 115-152. 